\section{Benefits of Multiple Sclerosis and Quality of Life. The mediating role of coping strategies}

González-Castro, J.L.; Ubillos Landa, S., Sarabia Montaño, V.

University of Burgos, Spain

jlgoca@ubu.es

Multiple sclerosis (MS) is a chronic demyelinating disease of the central nervous system (CNS) characterized by localized areas of inflammation, demyelination, axona loss and gliosis in the brain and spinal cord.

Since there is currently no cure for MS improving the Health-Related Quality of Life (HRQOL) of those affected by the disease is of great importance.

Coping strategies are closely linked to chronic diseases and patients' HRQOL. In MS, coping is a key mediator between the chronic disease and the patient's adjustment to their illness (Bianchi \& Pozzilli, 2015)

Coping is defined as the cognitive and behavioral efforts made to manage specific external and/or internal demands that are appraised as taxing or exceeding one's resources (Folkman, Lazarus, DunkelSchetter, DeLongis \& Gruen,1986)

Coping strategies are usually divided into two types: problem-focused responses (active efforts to change the stressful event) and emotion-focused responses (attempts to modify or regulate the emotional response generated by the stressful event) (Roubinov, Turner \& Williams, 2015)

Benefit finding is a process by which an individual makes sense of significant negative events in order to foster adjustment. It is the process of identifying benefits in adversity. It is inked to less depression and more positive well-being, but also to more intrusive and avoidant thoughts about the stressor (Helgeson, Reynolds, \& Tomich, 2006) between the perceived benefits of the
Objectives: Test those variables (demographical, psychoogical and social) that explain HRQOLL. We also expected coping strategies to mediate the relationship disease and HRQOL.

Methodology: Cross-sectional study. 250 over 18 participants from Spain, diagnosed with MS 73 men $(29.2 \%)$ and 177 women $(70.8 \%)$ mean age of $41.74 \quad(S D=10.34$; range 19-71)

The scales applied were: a) FAMS (Cella et al., 1996) measures the HRQOL of people with MS. B) COPE-28 (Morán, Landero \& González, 2010) evaluates different forms of coping and c) Psychosocial impact of multiple sclerosis (Morh et al., 1999) measures the psychosocial impact of MS in affected people, specifically the dimension of benefits derived from MS.

Results: A Multiple Linear Regression Analysis was used to test predictor variables of $\mathrm{HRQOL}$ (see table 1)

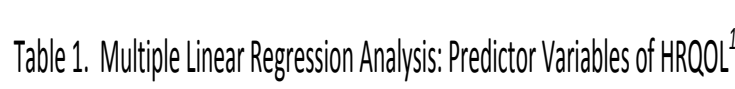

\begin{tabular}{|c|c|c|c|c|c|c|}
\hline \multicolumn{7}{|c|}{ HRQOL } \\
\hline Predictors & B & SE & $B$ & $t$ & $p$ & C195\% \\
\hline Employment situation ${ }^{2}$ & .19 .595 & 4.122 & .291 & -4.754 & .0001 & $27,117 /-114.472$ \\
\hline Planning & -3.397 & 1.384 & -169 & -2.454 & .015 & $-6.1241:-670$ \\
\hline Emotional support & 3.199 & 1.559 & .161 & 2.052 & .041 & $.127 / 6.271$ \\
\hline Acceptance & 6.086 & 1.500 & .261 & 3.001 & .0001 & 3.01199 .160 \\
\hline Denial & -3.273 & 1.561 & .139 & -2.097 & .037 & $-6.348 / 197$ \\
\hline Self-distration & -2.492 & 1.174 & .131 & -2.122 & .035 & $-4.806-1.177$ \\
\hline$R=601, R^{2}=361$, & $20207=6.4$ & $407,0=00$ & & & & \\
\hline
\end{tabular}

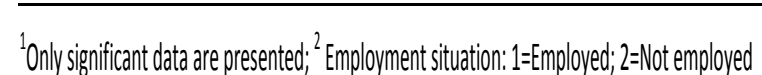

Results in table 1 show that being employed Bianchi, V, \& Pozzilli, C. (2015). Coping and Multiple Sclerosis. In Brochet B. (ed.) Neuropsychiatric Symptoms of Inflammatory Demyelinating Diseases. Université de Bordeaux, France: Springer; 2015. p.121-138 Cella, DF, Dineen, K, Arnason, B, Reder, A, Webster, KA, Karabatsos, G, \& Stefoski, D. (1996). Validation of the functional assessment of multiple sclerosis quality of life instrument. Neurology 47(1): 129-139.
Folkman, S, Lazarus, RS, Dunkel-Schetter, C, DeLongis, A, \& Gruen, RJ. (1986). Dynamics of a stressful encounter: cognitive appraisal, coping, and encounter outcomes. $J$ Pers So Psychl, 50(5): $992-1003$ Folkman, S, Lazarus, RS, Dunkel-Schetter, C, DeLongis, A, \& Gruen, RJ. (1986). Dynamics of a stressful encounter: cognitive appraisal, coping,

Mohr, DC, Dick, LP, Russo, D, Pinn, J, Boudewyn, AC, Likosky, W, \& Goodkin, DE. (1999).The psychosocial impact of multiple sclerosis: Exploring the patient's perspective. Health Psychol 18(4): 376-82 Moran, C, Landero, R, \& Gonzalez, MT. (2010). COPE-28: un analisis psicométrico de la version en español del Brief COPE. (COPE-28: A psychometric analysis of the Spanish version of the Brief COPE) Universitas Psychol 9(2): 543-52 Roubinov, DS, Turner, AP, \& Williams, RM. (2015). Coping among individuals with multiple sclerosis: Evaluating a goodness-of-fit model. Rehabil Psychol 60(2): $162-68$ engaging less in planning, denial and selfdistraction and more in emotional support and acceptance predicted a more positive $\mathrm{HRQOL}$, explaining $30.5 \%$ of the variance

A mediation model (figure 1) tested the mediation effects of coping on benefits and HRQOL.

Benefit finding did not have a significant effect on HRQOL. However, it had a positive and significant effect on acceptance, emotional support, planning and selfdistraction

Acceptance and emotional support were found to positively and significantly affect HRQOL, while denial, planning and selfdistraction had a significant negative effect on the same variable. Moreover, being employed predicted a more positive HRQOL $(\mathrm{B}=-21.12, \mathrm{SE}=3.63, \mathrm{Cl} 95 \%-28.26 /-13.98)$.

The indirect effect test revealed that acceptance $(\mathrm{B}=2.96, \quad \mathrm{SE}=1.63, \quad \mathrm{Cl} 95 \%$ 07/6.44), emotional support ( $\mathrm{B}=3.93$, $\mathrm{SE}=1.72$, Cl 95\% .82/7.60), planning ( $\mathrm{B}=-$ 2.47, $\mathrm{SE}=1.17, \mathrm{IC} 95 \%-5.09 /-.57)$ and selfdistraction ( $\mathrm{B}=-1,68, \mathrm{SE}=.91, \mathrm{IC} 95 \%-3.64 /-$ 12) explained the relationship between benefit finding and HRQOL. Denial had no significant mediating affect $(\mathrm{B}=-.24, \mathrm{SE}=.71$, IC 95\% -1.57/1.34).

Discussion: Employment situation was a powerful predictor of HRQOL. Coping strategies such as planning, denial and selfdistraction predicted a poorer HRQOL. The strategies that fostered a more positive HRQOL, on the other hand, were acceptance and emotional-social support.

Benefit finding was not directly associated with HRQOL. Nevertheless, as hypothesized, different coping strategies were found to mediate the relationship between the two variables.
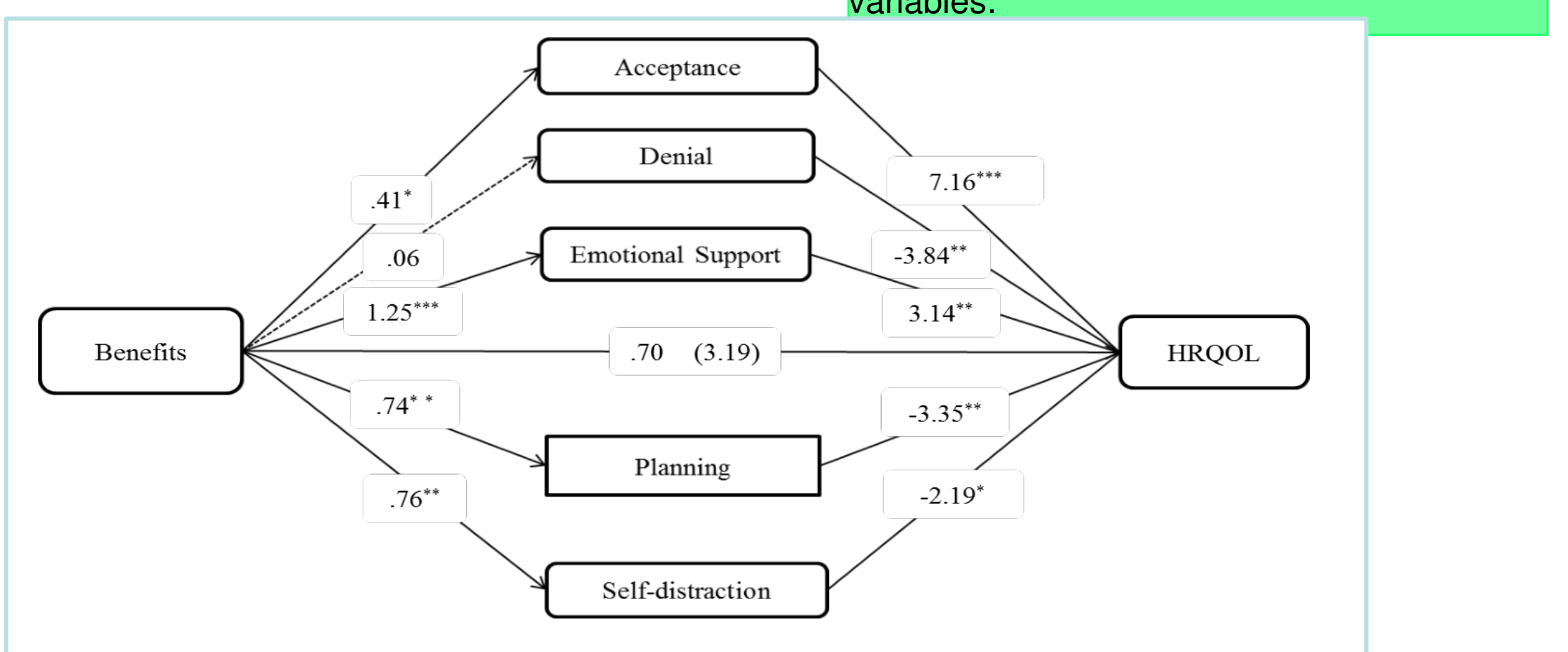